\title{
Formulation of low cost eco-repair mortar based on dune sand and Stipa tenacissima microfibers plant
}

\author{
Benharzallah Krobba ${ }^{a}$, Mohamed Bouhicha ${ }^{a}$, Said Kenai ${ }^{b, *}$, Luc Courard ${ }^{c}$ \\ ${ }^{a}$ Structures Rehabilitation and Materials Laboratory, University of Laghouat, Algeria \\ ${ }^{\mathrm{b}}$ Geomaterials Laboratory, University Saâd Dahlab-Blida1, Blida, Algeria \\ ${ }^{\mathrm{C}}$ Urban and Environmental Engineering, ArGEnCo Department, Liège University, Belgium
}

\section{H I G H L I G H T S}

- The use of Alfa micro-fiber increases compressive and flexural strengths and decreases shrinkage.

- Mortar with $0.75 \%$ fibers present a very good resistance to gas permeability and lower sorptivity.

- Mortar with fibers has a bond strength higher than that of ordinary mortar.

\section{A R T I C L E I N F O}

\section{Article history:}

Received 4 September 2017

Received in revised form 2 March 2018

Accepted 21 March 2018

\section{Keywords:}

Microfibers plant

Dunesand

Repair mortar

Shrinkage

Mechanical strength

Gas permeability

Sorptivity

Bonding strength

Adhesion

\begin{abstract}
A B S T R A C T
Mortar for patch repair of damaged concrete elements by corrosion or honeycombing are extensively used. However, they are quite expensive and they frequently incorporate low volume of synthetic fibers. This paper presents an experimental study on the development of an eco-repair mortar based on dune sand and microfibers plant. The vegetable fibers are 3-5 $\mathrm{mm}$ long Alfa microfibers plant (Stipa tenacissima L.) and are used with different volume ratios. The physical and mechanical properties investigated are compressive strength, flexural strength, shrinkage and bonding strength. The durability of mortar was evaluated through gas permeability and capillary water absorption tests. The results obtained show an enhancement of the mechanical and physical properties of mortars with natural microfibers compared to those of mortars without natural fibers. A lower sorptivity and a lower gas permeability were also obtained for the repair mortar reinforced with microfibers plant.
\end{abstract}

(c) 2018 Elsevier Ltd. All rights reserved.

\section{Introduction}

Construction industry consumes large amounts of natural resources and energy and there is a need for using local and natural renewable materials such as natural fibers and recycled materials. In addition, reinforced concrete infrastructures deteriorate with age and under aggressive environments such as hot climate. Hence, there is need to rehabilitate and repair old reinforced concrete structures such as historical buildings, wharfs and bridges. The repair mortar used for corroded concrete structures is usually a cement based mortar with and without fibers. In North Africa region, the repair mortar is costly as it is mainly imported from Europe and there is a need for formulating mortar using local

\footnotetext{
* Corresponding author.

E-mail address: sdkenai@yahoo.com (S. Kenai).
}

materials such as dune sand and natural fibers to reduce cost. Natural fibers are cheap and readily available and require low energy for their production as compared to synthetic fibers.

Dune sand is available in large quantities in the Sahara and is covering over $60 \%$ of the area of Algeria. Recently, there has been a growing interest in sand dune as construction material [1-4]. Dune sand is used as a replacement to manufactured sand river and river sand which its use is restricted for environmental reasons and hence help preserving natural resources.

In fiber-reinforced mortars, fibers are usually synthetic polyethylene or polypropylene fibers and are discontinuous and randomly distributed throughout the composite. Random dispersion of fibers delay cracks and limits their openings through the effects of bridging transmitted to the fracture surfaces [5-9]. However, to produce ecofriendly mortar, the use of recycled fibers such as foamed recycled fibers, recycled steel fibers from waste tires or 
lathe metal workshop, waste polypropylene fibers from storage bags and recycled nylon fibers have been used to get more sustainable cement mortar composites [10-14] or vegetable fibers as reinforcement is a viable way for achieving a more sustainable construction $[15,16]$. Vegetable fibers are considered as a renewable resource, stronger than synthetic fibers, less costly and environment friendly. Natural fibers include among others coconut, sisal, jute, Hibiscus cannabinus, eucalyptus grandis pulp, malva, ramie bast, pineapple leaf, kenaf bast, sansevieria leaf, abaca leaf, vakka, date, bamboo, palm, banana, hemp, flax, cotton and sugarcane fibers [17]. The incorporation of fibers into cementitious materials can effectively improve their toughness and can control drying plastic shrinkage cracks [18-23]. Other advantages of vegetable fibers in cement composites include increased flexural strength, post-crack load bearing capacity, increased impact toughness and improved bending strength, cost reduction and benefits associated with processing, compared to synthetic fibers [24-26]. Vegetable fibers are eco-friendly materials as they are obtained from renewable sources. However, they are considered as biodegradable [27]. Natural fibers, recycled PET fibers and wood fibers have been reported to degrade when embedded in cement matrix $[28,29]$.

Alfa grass (Stipa tenacissima L.) is a tussock grass widely distributed in semi-arid and arid regions, in North Africa and southern Spain. This perennial grass, also named Esparto grass, is used as a main source of fiber for paper making. Algeria has an area of more than 3 million hectares of Alfa fibers. Currently, Alfa is well known for paper applications as a raw material but it is not used in cement composite applications. In this paper, the effect of adding simultaneously this local vegetable fibers and dune sand to produce a sustainable and economical patch repair mortar is investigated. Fibers are added to reduce the shrinkage cracking of the repair mortar and reduce the risk of its carbonation and therefore reduce the risk of corrosion.

The most important characteristics of a patch repair mortar are its flowability, bond strength, mechanical strength, low shrinkage and protection from aggressive environments. The protection of repair mortar to concrete could be assessed by water absorption by capillary and gas permeability which could be a good indicators for resistance to water penetration and carbonation. The experimental work presented in this paper analyzes the effect of incorporation of Alfa vegetable fibers on physical and mechanical characteristics of dune sand repair mortar as well as its durability through gas permeability and water absorption by capillary tests. The adhesion characteristics of repair mortars on concrete substrate is also evaluated by means of pull-off tests.

\section{Experimental details}

\subsection{Materials and mix proportions}

Portland cement type CEM II A 42.5 according to the European standard EN 197-1 was used. The dune sand used was extracted from the Algerian desert in northern region of the city of Laghouat, $400 \mathrm{~km}$ South of Algiers and has a fineness modulus of 0.84 and granular size of $(0 / 0.5)$. The grading curve of dune sand is presented in Fig. 1. SEM investigations reveal the relatively rounded shape grains with some irregular and angular grains of dune sand (Fig. 2). The EDX analysis demonstrates the essentially siliceous nature of dune sand (Fig. 3). A sulfated polymelamine superplasticizer (SP) admixture called Medaplast SP40 was used. The microfibers plant used are Stipa Tenacissima type (called Alfa fibers) cut by hand to $3-5 \mathrm{~mm}$ length and presents a dimeter of $150-250$ $\mu \mathrm{m}$. The chemical and physical properties of the cement are presented in Table 1 while the main characteristics of the Stipa

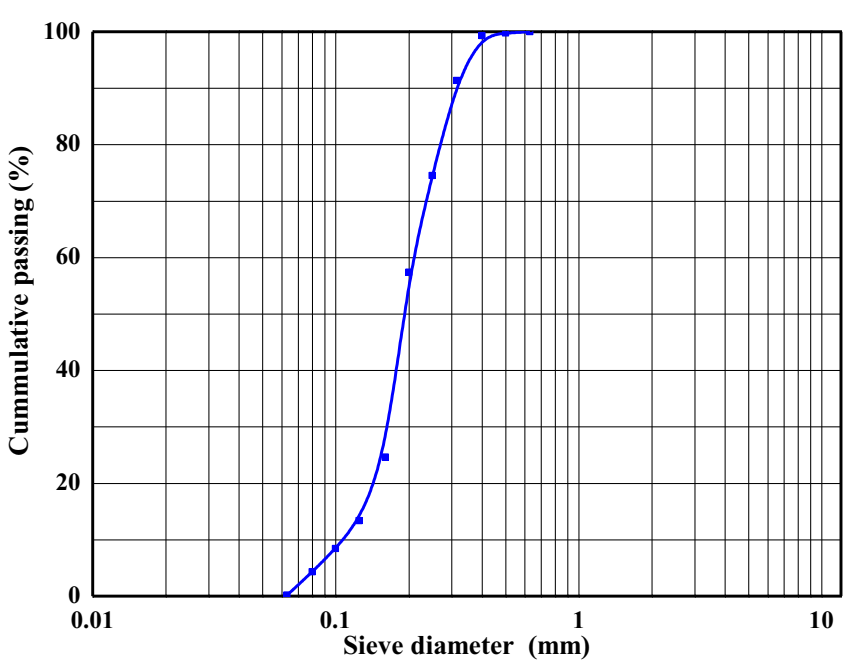

Fig. 1. Particle size distribution.

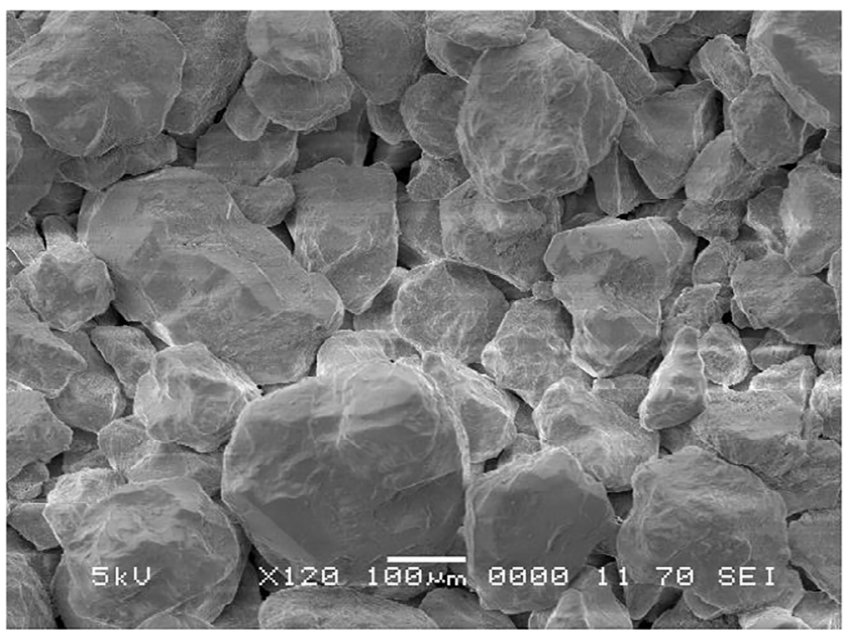

Fig. 2. Algerian desert dune sand SEM image.

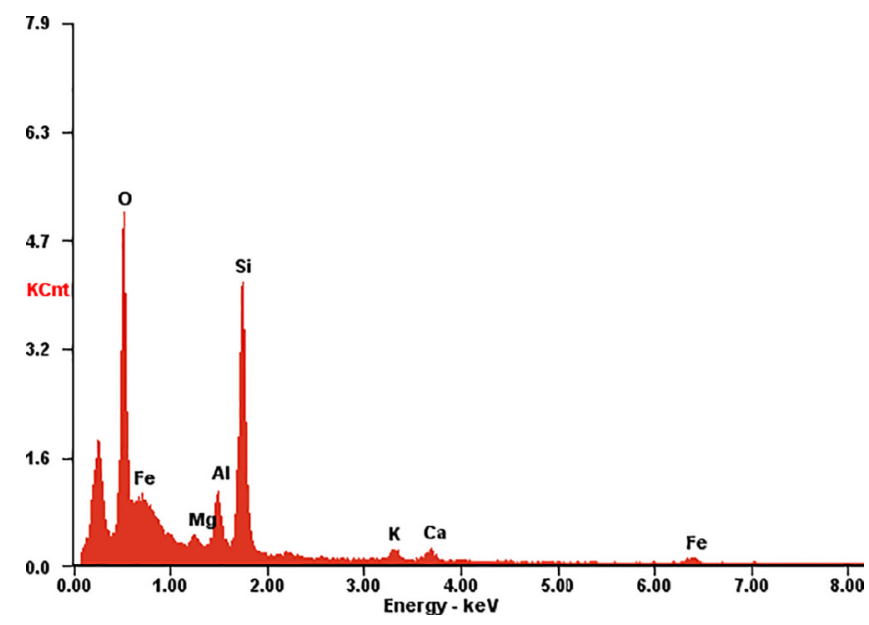

Fig. 3. Dune sand EDX analysis.

Tenacissima fibers are reported in Table 2. It can be clearly seen that the characteristics of the fibers present a large variability and hence these characteristics are given as range and not fixed 
Table 1

Compositions of cement

\begin{tabular}{llll}
\hline Chemical & $\%$ & Mineralogical Composition & $\%$ \\
\hline $\mathrm{SiO}_{2}$ & 19.70 & $\mathrm{C}_{3} \mathrm{~S}$ & 60.31 \\
$\mathrm{Al}_{2} \mathrm{O}_{3}$ & 4.52 & $\mathrm{C}_{2} \mathrm{~S}$ & 17.41 \\
$\mathrm{Fe}_{2} \mathrm{O}_{3}$ & 3.49 & $\mathrm{C}_{3} \mathrm{~A}$ & 6.13 \\
$\mathrm{CaO}$ & 60.15 & $\mathrm{C}_{4} \mathrm{AF}$ & 11.97 \\
$\mathrm{MgO}$ & 1.79 & Physical properties & \\
$\mathrm{SO}_{3}$ & 2.27 & Specific Density & 3.04 \\
$\mathrm{~K}_{2} \mathrm{O}$ & 0.49 & Specific Surface $\left(\mathrm{cm}^{2} / \mathrm{g}\right)$ & 4010 \\
$\mathrm{Na}_{2} \mathrm{O}$ & 0.25 & & \\
$\mathrm{Cl}$ & 0.02 & & \\
$\mathrm{IR}$ & 1.50 & & \\
$\mathrm{LOI}$ & 5.82 & & \\
\hline
\end{tabular}

Table 2

Stipa Tenacissima fibers characteristics.

\begin{tabular}{ll}
\hline Properties & Value \\
\hline Specific Density $\left(\mathrm{g} / \mathrm{cm}^{3}\right)$ & $0.92 \div 1.10$ \\
Natural moisture content (\%) & $4.9 \div 5.2$ \\
Water absorption after saturation (\%) & $180 \div 220$ \\
Tensile strength (MPa) & $103.6 \div 258.4$ \\
Modulus of elasticity (GPa) & $13.2 \div 17.7$ \\
Strain failure (\%) & $1.4 \div 2.7$ \\
Hemi-Cellulose (\%) & 25 \\
Cellulose (\%) & $43.4 \div 47.6$ \\
Lignin (\%) & $17.7 \div 24.3$ \\
Extractions and others & 7 \\
\hline
\end{tabular}

values. The SEM images of Stipa tenacissima L. microfibers plant are displayed in Fig. 4. Fig. 5(a) and (b) present the rough surface of fibers that can contribute to the good adhesion between the fibers and matrix. Fig. 5(c) shows the interfacial zone between fiber and matrix.

The experimental study was carried out on a simple mortar MS (cement + sand + water), admixture mortar MA (cement + sand + water + SP) and fiber mortar MV (cement + sand + water + admixture + fiber). Table 3 presents details of the different mixes used. The SP was used at $2 \%$ of binder weight to improve the flowability of all mixtures and to maintain approximately the same flow. The flow is the resulting increase in average base diameter of the mortar mass, expressed as a percentage of the original base diameter and the target flow was $110 \pm 5 \%$ according to ASTM C 1437 [30]. Eight microfiber volume ratios by mortar volume of $0.10,0.20$, $0.30,0.40,0.50,0.75,1.00$, and $1.25 \%$, respectively, were used to prepare the mixtures MV1 to MV8. The microfibers were completely saturated in water during $24 \mathrm{~h}$ before their incorporation in matrix to avoid immigration of water from matrix to the fibers and therefore promote the hydration of cement around the fibers which can lead to good microfiber-matrix bond.
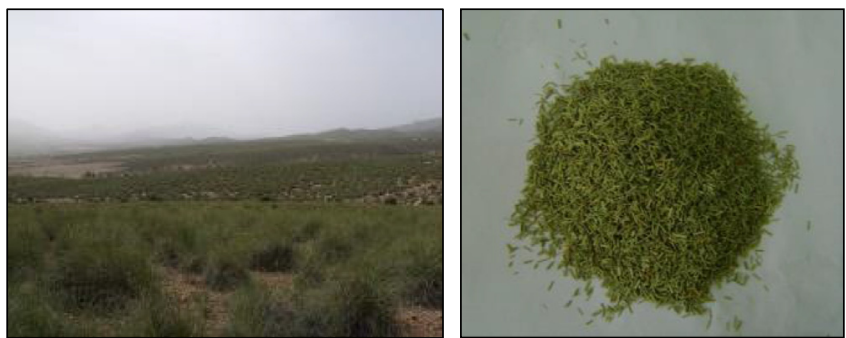

Fig. 4. Illustrations of the Alfa fibers.

\subsection{Experimental methods}

The choice of a repair mortar on site is usually based on their short term properties such as strength, bond and early age shrinkage and on the protection of the concrete substrate.

The mortar mixtures were prepared in accordance with ASTM C 305 [31]. The flow table was used to adjust the flow within $110 \pm$ $5 \%$. Mortar mixes were cast in prismatic molds $(40 \times 40 \times 160$ $\mathrm{mm}^{3}$ ) in accordance with ASTM C 348 [32]. The molds containing the samples were covered by plastic film, and stored in a $20 \pm 2 \mathrm{C}$ - climatic room. After $24 \mathrm{~h}$, the samples were removed from the molds and stored, until the age of testing, in saturated limewater at $(20 \pm 2)^{\circ} \mathrm{C}$ for mechanical tests and in the environmental room $(20 \pm 2){ }^{\circ} \mathrm{C}$ and $(50 \% \pm 2 \%)$ of relative humidity (R.H) for shrinkage tests.

The flexural and compressive strength tests of each mix proportions were conducted at 28 days. For flexural strength, three specimens from each mix were prepared and tested with a three-point bending configuration according to ASTM C348. Six portions of the mortar prisms tested in flexure were used for the determination of compressive strength in accordance with ASTM C 349 [33].

The drying shrinkage measurements were performed for all mortars on three prismatic sections $(40 \times 40 \times 160) \mathrm{mm}$ specimens up to 28 days after an initial curing of one day in the mould in accordance with NF P15-433 standard practice [34].

The water absorption test by capillarity helps for characterizing the water transfer capacity of a mortar to absorb and transmit water by capillarity. In this study, the test is performed on $40 \times$ $40 \times 160 \mathrm{~mm}$ prismatic samples previously dried in the oven at about $80^{\circ} \mathrm{C}$ until constant weight. They are then placed in tray such that their bottom surface up to a $5 \mathrm{~mm}$ is in contact with water. Lateral sealing is provided by means of an adhesive tape to obtain a unidirectional flow. The weight of specimens is measured at various times: 6, 18, 30, 60, 120, 180, 720, 1080 and $1440 \mathrm{~min}$. The capillary absorption test was carried out after 28 and 180 days of curing.

The first six hours rate of water absorption was registered for determining the initial absorption known as "sorptivity" of the concrete [35].

The cumulative mass of water absorbed per unit of inflow surface (cross sectional area) at each time interval was evaluated and the sorptivity determined from the slope of the function of the water absorbed in function of the square root of time by the following equation:

$\frac{Q}{A}=S_{c} \sqrt{t}$

$\mathrm{Q}$ : is the cumulative water absorbed in $(\mathrm{g})$; $\mathrm{A}$ is the cross-sectional area $\left(\mathrm{cm}^{2}\right)$; $t$ the elapsed time in $(\mathrm{min})$ and $\mathrm{S}_{\mathrm{c}}$ is the sorptivity coefficient of the specimen $\left(\mathrm{g} / \mathrm{cm}^{2} \cdot \mathrm{min}^{0.5}\right)$.

The gas permeability is a transfer property that is commonly used to characterize the durability of concrete. From this point of view, it can be a good indicator of durability [36]. Permeability of repair mortars is very critical for the protection of parent concrete as they are the first line of resistance against ingress of deleterious agents such as oxygen and carbon oxide. The Nitrogen gas permeability test was performed using the CEMBUREAU method according to NF XP P18-463 [37] for each type of mortar at 28 and 180 days is shown in Fig. 6. A specimen was subjected to a constant gas pressure $\mathrm{Pi}$ (inlet pressure). The apparent permeability $\mathrm{K}_{\mathrm{a}}$ was calculated under five inlet pressure gradients from 1 to 3 bars in increments of 0.5 bar gas flow permanent regime according to the following equation:

$K_{a}=\frac{2 \cdot P_{i} \cdot Q \cdot L \cdot \mu}{A\left(P_{i}^{2}-P_{0}^{2}\right)}$ 

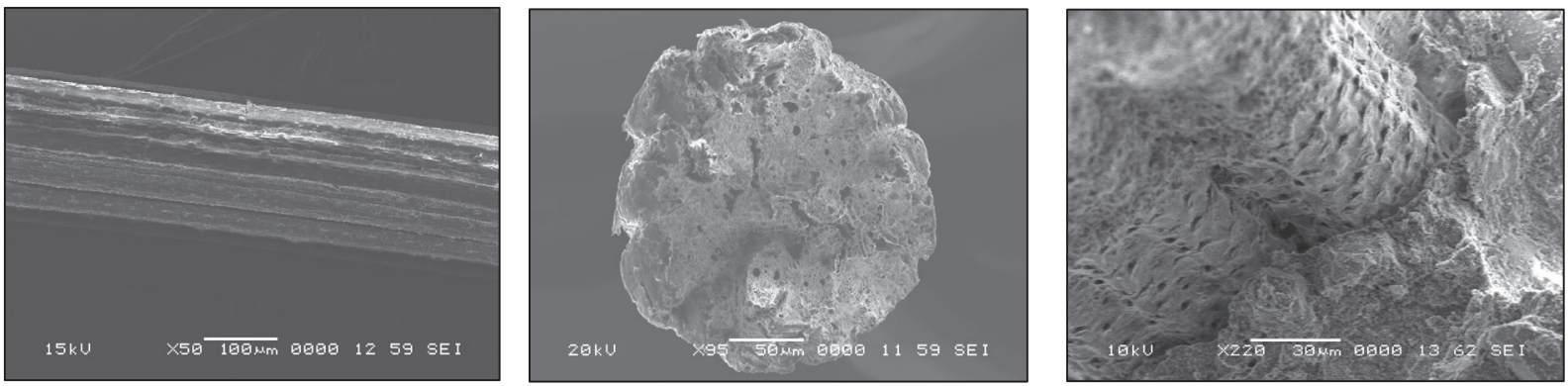

Fig. 5. SEM images of Alpha fibers (a) side view (b) transversal section (c) interfacial zone fiber/matrix.

Table 3

Mixtures compositions.

\begin{tabular}{|c|c|c|c|c|c|c|}
\hline Index & Cement $\left(\mathrm{kg} / \mathrm{m}^{3}\right)$ & Sand $\left(\mathrm{kg} / \mathrm{m}^{3}\right)$ & Water $\left(\mathrm{kg} / \mathrm{m}^{3}\right)$ & $\mathrm{SP}(\%)$ & Fibers vol. (\%) & Flow (\%) \\
\hline MS & 450 & 1350 & 315 & 0 & 0 & 110 \\
\hline MA & 450 & 1350 & 270 & 2 & 0 & 110 \\
\hline MV1 & 450 & 1350 & 270 & 2 & 0.1 & 109 \\
\hline MV2 & 450 & 1350 & 270 & 2 & 0.2 & 109 \\
\hline MV3 & 450 & 1350 & 270 & 2 & 0.3 & 109 \\
\hline MV4 & 450 & 1350 & 270 & 2 & 0.4 & 109 \\
\hline MV5 & 450 & 1350 & 270 & 2 & 0.5 & 108 \\
\hline MV6 & 450 & 1350 & 270 & 2 & 0.75 & 108 \\
\hline MV7 & 450 & 1350 & 270 & 2 & 1 & 108 \\
\hline MV8 & 450 & 1350 & 270 & 2 & 1.25 & 108 \\
\hline
\end{tabular}
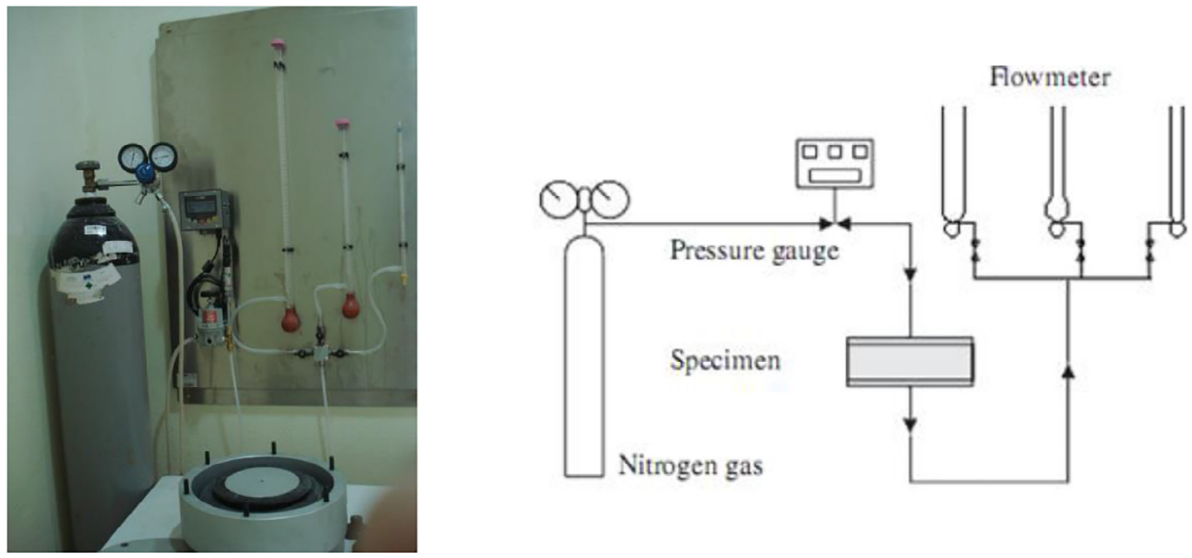

Fig. 6. Cembureau gas permeability test set-up.

L: thickness of the sample (m)

A: cross-sectional area $\left(\mathrm{m}^{2}\right)$

$\mathrm{Q}$ : measured gas flow $\left(\mathrm{m}^{3} . \mathrm{s}^{-1}\right)$

$\mu$ : dynamic viscosity coefficient of nitrogen gas $\left(17,5 \times 10^{-6} \mathrm{~Pa}\right.$. s)

$\mathrm{P}_{\mathrm{i}}$ : inlet absolute pressure $(\mathrm{Pa})$

$\mathrm{P}_{0}$ : atmospheric pressure $(\mathrm{Pa})$

The approach of Klinkenberg is used to get the value of intrinsic permeability $\mathrm{K}_{\mathrm{v}} \cdot \mathrm{K}_{\mathrm{v}}$ is the limiting value of gas permeability when the medium pressure Pm tends toward infinity. The determination of $\mathrm{K}_{\mathrm{v}}$ consists in measuring $\mathrm{K}_{\mathrm{a}}$ at different pressures $\left(\mathrm{P}_{\mathrm{i}}\right)$ and in plotting it against the inverse of the medium pressure $(1 / \mathrm{Pm})$.

$K_{a}=K_{v}\left(1+\frac{\beta}{P_{m}}\right)$

With:

$P_{m}=\frac{P_{i}+P_{0}}{2}$
$\mathrm{P}_{\mathrm{m}}:$ medium gas pressure $(\mathrm{Pa})$

$\beta$ : Klinkenberg coefficient $(\mathrm{Pa})$

The bonding between repair mortar and concrete substrate is one of the most important factors for the success of patch repair works in concrete structures. Good bonding of repair mortar avoids substrate-repair debonding.

The bond strength of the repair materials was determined using the pull-off test as described in standard EN 1542 test procedure [38]. In order to realize the pull-off test for different types of mortars, three reference concrete slabs (substrates) were produced using the mixing ratios given in Table 4 . The substrates have been covered with polythene film for $24 \mathrm{~h}$ after casting at a temperature of $(20 \pm 2){ }^{\circ} \mathrm{C}$, demolded and stored in saturated lime-water at $20 \pm$ $2{ }^{\circ} \mathrm{C}$. When the concrete substrate was 28 days old the concrete substrate surface was prepared at the required roughness and the repair mortar was then applied. The bonding strength was tested after 28 and 180 days by drilling core samples and using the pull-off test method. The specimens' preparation is shown in Fig. 7. The reference concrete slab specimens (substrates) of 30 
Table 4

Mix proportions and properties of normal concrete used for substrate concrete.

\begin{tabular}{ll}
\hline Cement $\left(\mathrm{kg} / \mathrm{m}^{3}\right)$ & 350 \\
\hline sand $\left(\mathrm{kg} / \mathrm{m}^{3}\right)$ & 726 \\
Gravel $3 / 8\left(\mathrm{~kg} / \mathrm{m}^{3}\right)$ & 150 \\
Gravel $8 / 15\left(\mathrm{~kg} / \mathrm{m}^{3}\right)$ & 916 \\
$\mathrm{~W} / \mathrm{C}$ & 0.61 \\
Slump $(\mathrm{mm})$ & 70 \\
Density & 2.350 \\
28 days Compressive strength (MPa) & $30 \pm 2$ \\
28 days Flexural Strength (MPa) & $6.5 \pm 0.5$ \\
\hline
\end{tabular}

$\times 30 \times 10 \mathrm{~cm}$ were fabricated, according to the EN 1766 standard [39], from a cement CEM II/B 42.5. Table 4 shows details of the different compositions.

The bond strength $(\boldsymbol{\sigma})$ is defined as the tensile (pull-off) force (F) divided by the area of the test specimen: the load rate should be applied at a stress rate of $35 \pm 15 \mathrm{kPa} / \mathrm{s}$ until failure occurs. The configuration is schematically showed in Fig. 8. The maximum tensile stress and failure mode was determined. The possible failure modes are showed in Fig. 9. These failure modes occurred: in substrate, at concrete/repair mortar interface, in repair mortar and at epoxy/disc interface.

The failure mode and the pull-off strength provide valuable information about the efficiency of repair system: if the failure occurs between the disc and the overlay surface, there is an adhesive failure. If failure occurs in the overlay material, the repair material is the weakest part of the system. This is referred as a cohesive failure of the overlay. Finally, if the fracture surface occurs in the concrete substrate, the repair system can be considered as adequate. This is often referred as a cohesive failure of the substrate [40].

\section{Analysis of the results and discussions}

\subsection{Effect of microfibers on mechanical strengths}

Fig. 10 shows the effect of adding fibers on the compressive strength of mortar. It is observed that the maximum value of the compressive strength is about 31.6 MPa corresponding to the optimum value of microfiber volume ratio (Vf) of $0.75 \%$. This enhancement of compressive strength may be attributed to the higher fiber/matrix bond and to the fiber crack bridging efficiency [41]. Beyond $0.75 \%$ volume of fiber, a drop in compressive strength is observed. This can be attributed to an increase in fiber contiguity and to difficulty in achieving good homogenization of the fresh mortar. Moreover, the low modulus of fibers and the high porosity brought by them could lead to lowering the mortars' compressive strength [42]. This is in accordance with the results reported by other authors $[27,43,44]$. Furthermore, the incorporation of microfibers in mortars led to a nearly linear increase in flexural strength as shown in Fig. 11. It can be observed that the higher

the volume fraction of fibers, the higher the maximum flexural load of the reinforced mortar. The increase in flexural strength could be could be attributed to the bridging effect as the fibers continue to deform and achieve higher load carrying capacity than that of plain mortar [42]. The maximum improvement in flexural strength of approximately 6.2 MPa was achieved for fiber volume ratio of $1.25 \%$ with the corresponding increase amounting to about $16 \%$. The irregular cross section of the used microfiber in this study (Alfa fiber) may be beneficial for the bond strength. It is observed that the optimum fiber volume ratio for compressive and flexural strengths is different. This could be attributed to the difference in testing mechanism as compression mechanism deals more with the hardness of materials and the distribution of stress throughout the whole matrix whereas the splitting resistance of the materials which is dependent on tensile strength, content, orientation and bonding with the matrix are dominant in the flexural strength [45].

\subsection{Effect of microfibers on total shrinkage}

Total shrinkage evolution as a function of the microfiber volume ratio is given in Fig. 12. It can be seen that a large amount of total shrinkage deformation is developed after two weeks. The effect of increasing the fiber content although favorable at the young age (decrease of shrinkage), gives an excessive value at 28 days. The effect of increasing fibers content does not give a clear trend probably because of the uncontrolled laboratory environment and the variability of fibers characteristics. However, the value of $V_{f}=$ $0.75 \%$ exhibits the lowest shrinkage at 28 days, with a decrease of $13.40 \%$ compared to that of control mortar (without fiber) as shown in Fig. 13. The reduced shrinkage can be attributed to the internal curing as vegetable fibers release their moisture within the matrix and hence reduces the autogeneous shrinkage. These results are consistent with the observations of other researches $[8,46]$. The results of this investigation suggest that a rate of fiber addition of $0.75 \%$ improves the compressive strength by $19 \%$, and the tensile strength by $7.5 \%$ and reduces shrinkage at about $13 \%$. As a consequence, this addition rate, which is comparable to the findings of other researchers, could be considered as the optimum value [27].

\subsection{Durability test results}

\subsubsection{Sorptivity}

The sorptivity is defined as the rate of water uptake by a porous material when exposed to a water source. A typical plot of the cumulative water absorption per unit surface area as a function of the square root of time is shown in Figs. 14 and 15. It can be seen that the cumulative weight of water absorbed per unit surface area $\left(\mathrm{g} / \mathrm{cm}^{2}\right)$ in the specimens increased with the square root of time for the different types of repair mortars at 28 and 180 days. Similar trends were observed for all the types of mortars (MS, MA, and MV6).

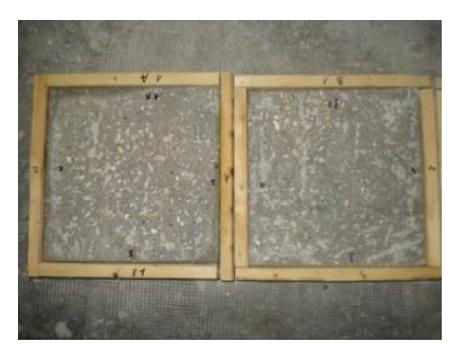

Substrate slabs placed in the mold

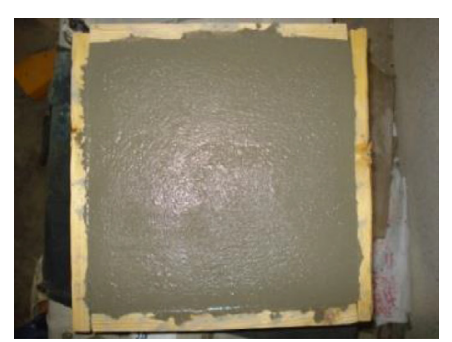

Substrate with applied repair mortar

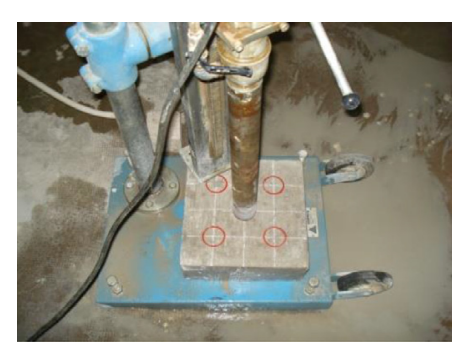

Drilling cores

Fig. 7. Sample preparation. 

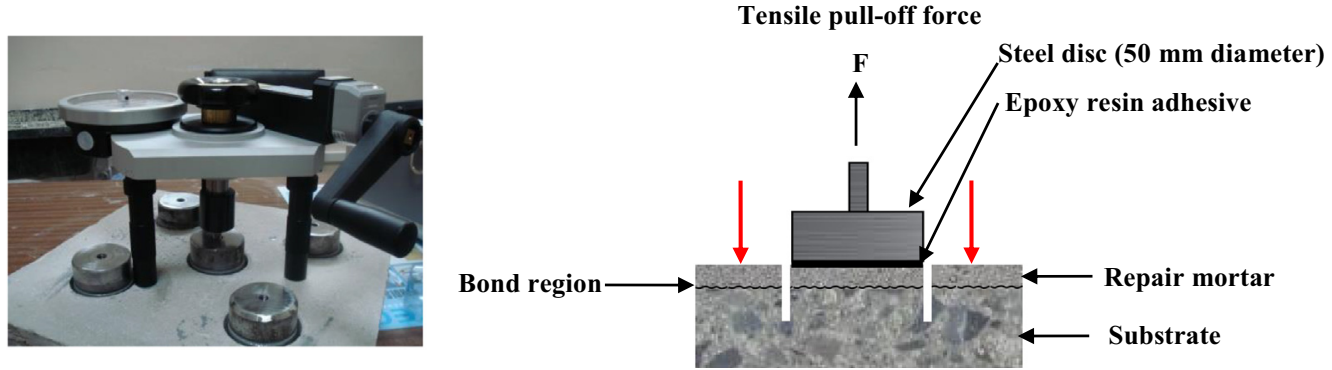

Fig. 8. Pull-off test schematic representation.
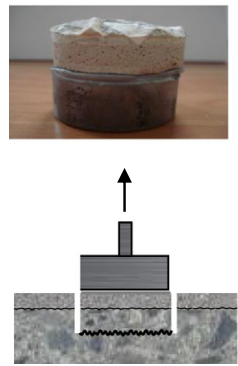

(a)
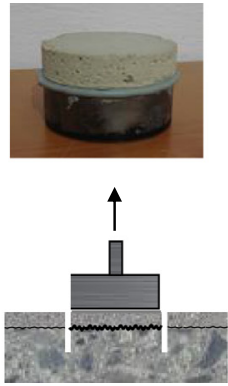

(b)
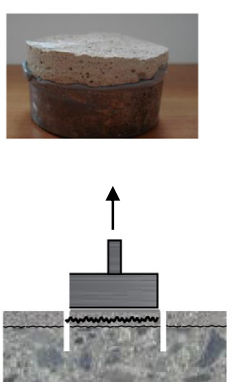

(c)

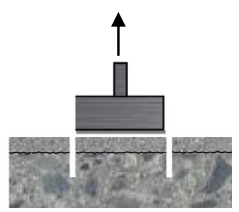

(d)

Fig. 9. Failure modes:(a) in substrate, (b) at concrete/repair mortar interface, (c) in repair mortar, (d) at epoxy/disc interface.

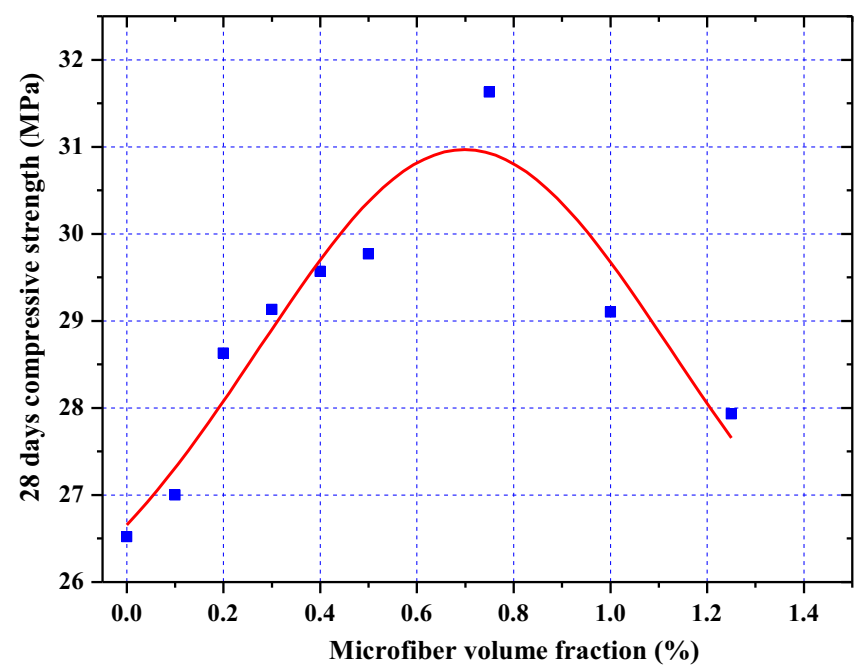

Fig. 10. Relationship between microfiber volume fraction and compressive strength.

The slope of each curve between 0 and $180 \mathrm{~min}$ is taken as the sorptivity coefficient of the tested mortars.

The sorptivity coefficients obtained at different ages are shown in Fig. 16. It should be noted that the sorptivity decreases with the increase of curing time (from 28 to 180 days) for all mortars tested by about $8 \%$. Moreover, mortars MA and MV6 offer lower absorption coefficient than mortar MS at both 28 and 180 days. Mortar MV6 has a value of $S_{c}$ of 0.023 and 0.021 at 28 and 180 days respectively which is about $27 \%$ lower than that of MS mortar. In addition, it can be seen that mortar MV6 has a coefficient of sorptivity higher than that of mortar MA of about $12 \%$. This can be attributed to the increase of volume of pores by the inclusion of fibers.

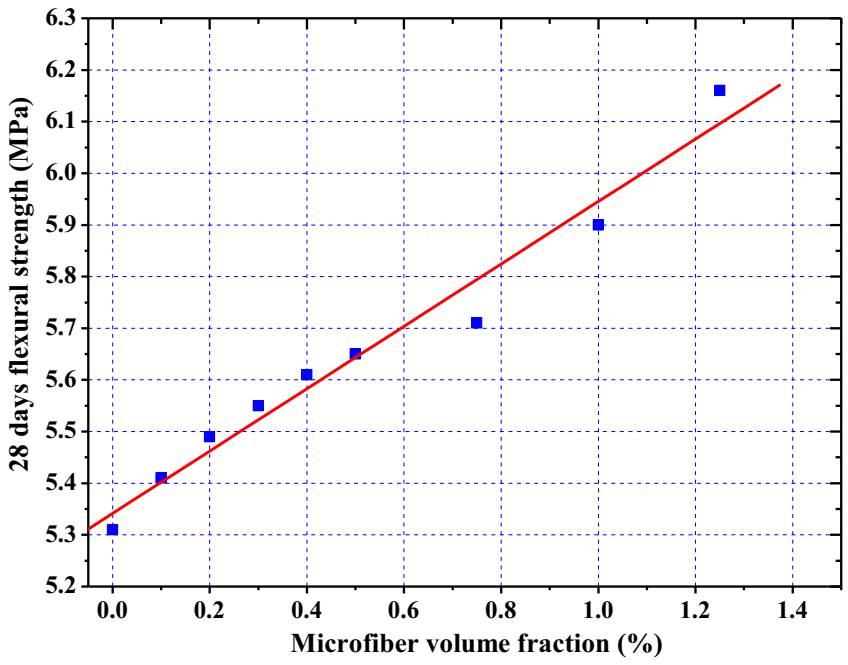

Fig. 11. Relationship between microfiber volume fraction and flexural strength.

\subsubsection{Gas permeability}

Permeability is a measure of the ability of a porous media to transmit fluids and gases under a gradient of pressure. Gas permeability approaches the permeability of mortar to air and hence an influencing factor for the compatibility of repair mortar with the original concrete.

Lower permeability means a good protection of the repair mortar to the repaired concrete. The average of the apparent permeability under different inlet pressures (1-3 bars) versus the inverse mean pressure $\left(1 / \mathrm{P}_{\mathrm{m}}\right)$ at 28 and 180 days are shown in Figs. 17 and 18, respectively. Linear interpolation of $K_{a}$ in function 


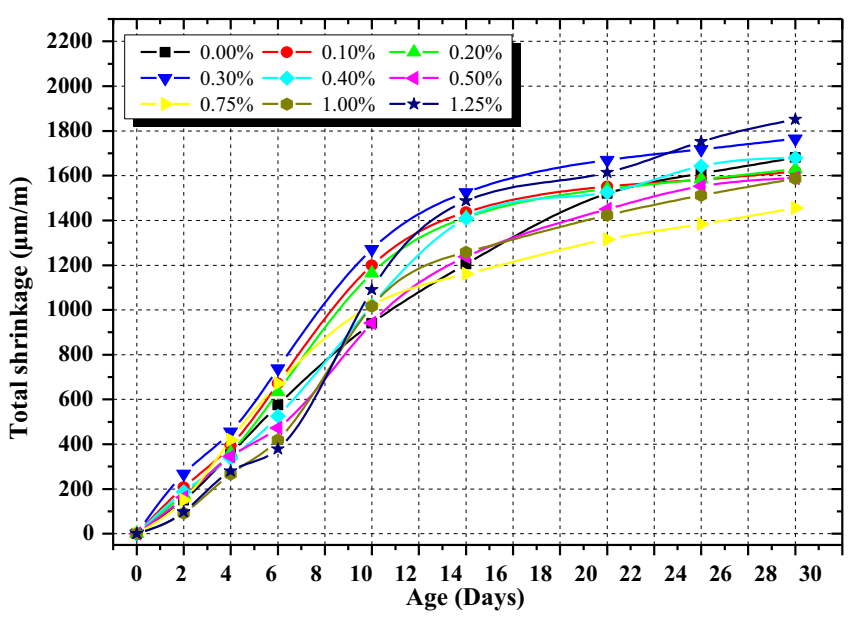

Fig. 12. Free shrinkage versus time.

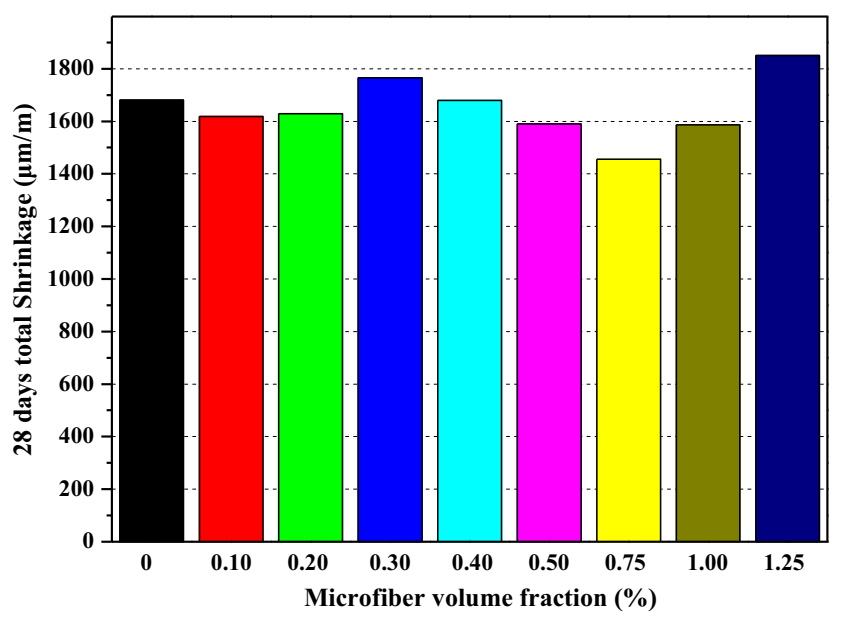

Fig. 13. Effect of the microfiber fraction on the 28 days shrinkage.

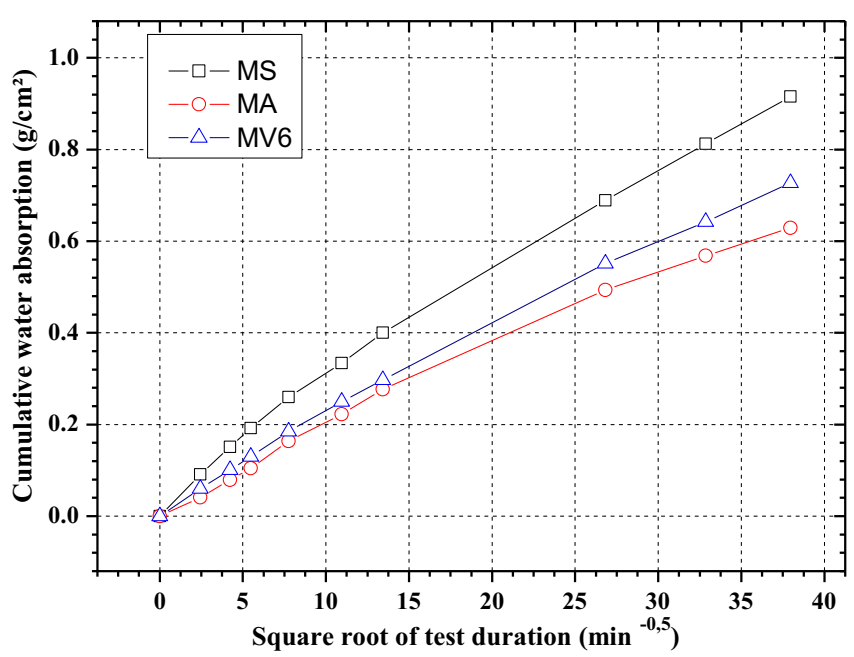

Fig. 14. Relationship between cumulative water absorption and time at 28 days.

of the inverse of the average pressure $\mathrm{P}_{\mathrm{m}}$ provides the intrinsic permeability $\mathrm{K}_{\mathrm{v}}$ which is the intersection of the curve with the X-axis at $1 / P_{m}=0$.

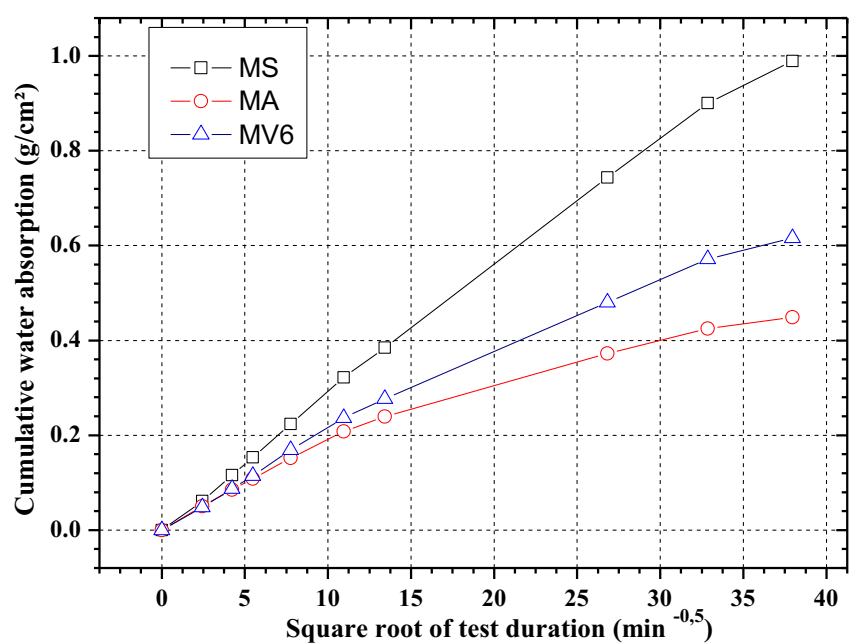

Fig. 15. Relationship between cumulative water absorption and time at 180 days.

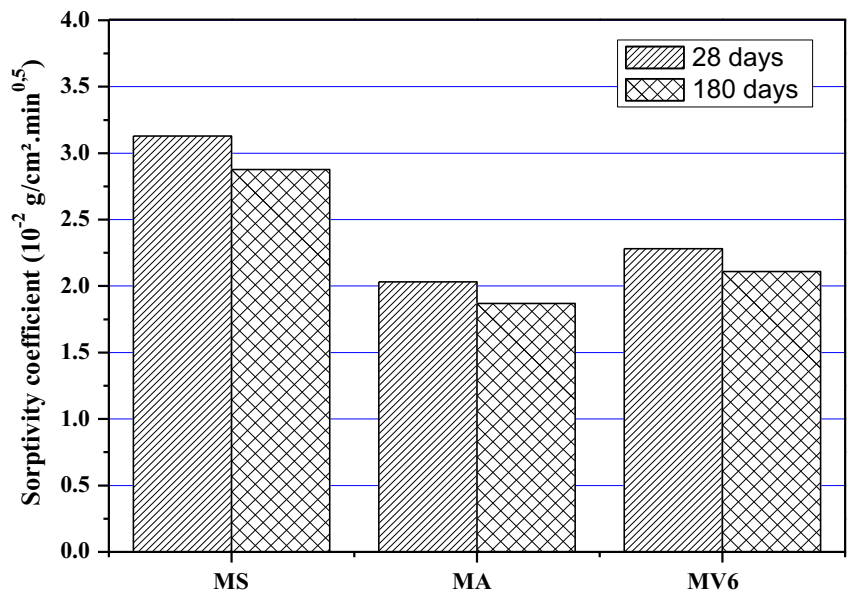

Fig. 16. Sorptivity coefficient of different mortars at 28 and 180 days.

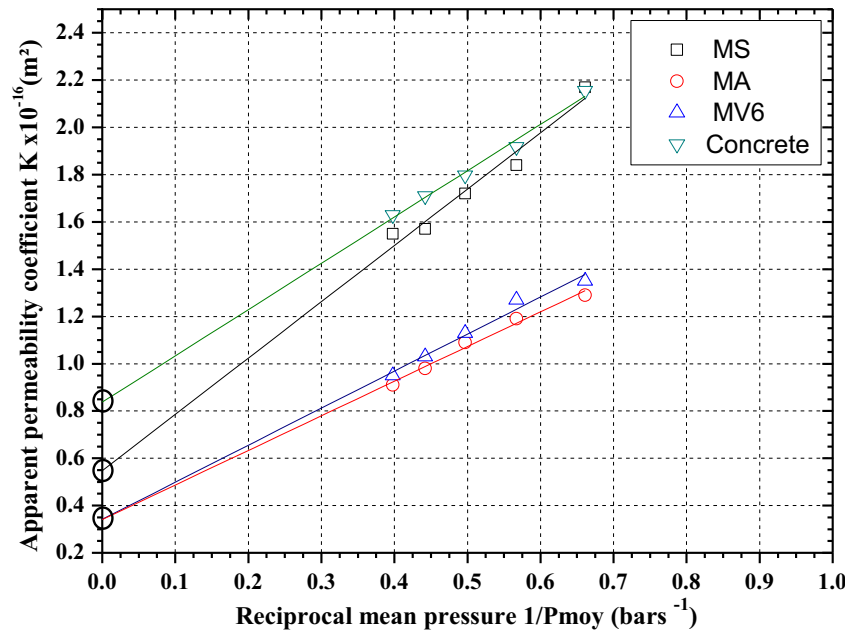

Fig. 17. Relationship between apparent permeability and inverse mean pressure at 28 days.

The values of the intrinsic gas permeability at 28 and 180 days are presented in Fig. 19. It should be noted that mortars MA and MV6 have lower intrinsic permeability coefficients than concrete and mortar MS at 28 and 180 days. The intrinsic permeability of 


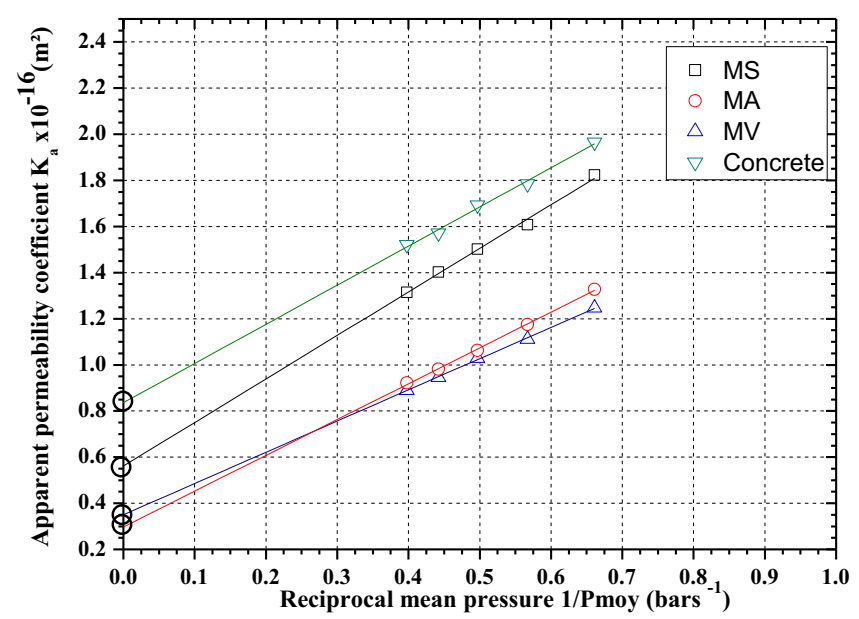

Fig. 18. Relationship between apparent permeability and inverse mean pressure at 180 days.

MA and MV6 are 38\% and 43\% lower than that of MS mortar at 28 days and 180 days, respectively. For all types of mortars and concrete, a decrease between $20 \%$ and $30 \%$ was observed in the gas permeability at 180 days compared to 28 days.

The decrease in intrinsic permeability can be attributed to the lower water/cement ratio in MA and MV6 mixes compared to mortar MS, which ultimately affects the reduction in capillary porosity of the system.

However, the gas permeability of different mortars remains below that of concrete and hence a better protection is provided. Referring to Table 5, which gives a qualitative classification of covercrete gas permeability; mortar MA and MV6 could be qualified as giving a very good resistance to gas permeability. These results are in agreement with the water absorption results.

\subsubsection{Relationship between sorptivity and gas permeability}

Fig. 20 shows the correlation between sorptivity and intrinsic permeability coefficient at 28 and 180 days for various repair mortars. It can be seen that the sorptivity coefficient is an increasing function of the intrinsic permeability coefficient. A linear correlation exists between the sorptivity and the intrinsic permeability

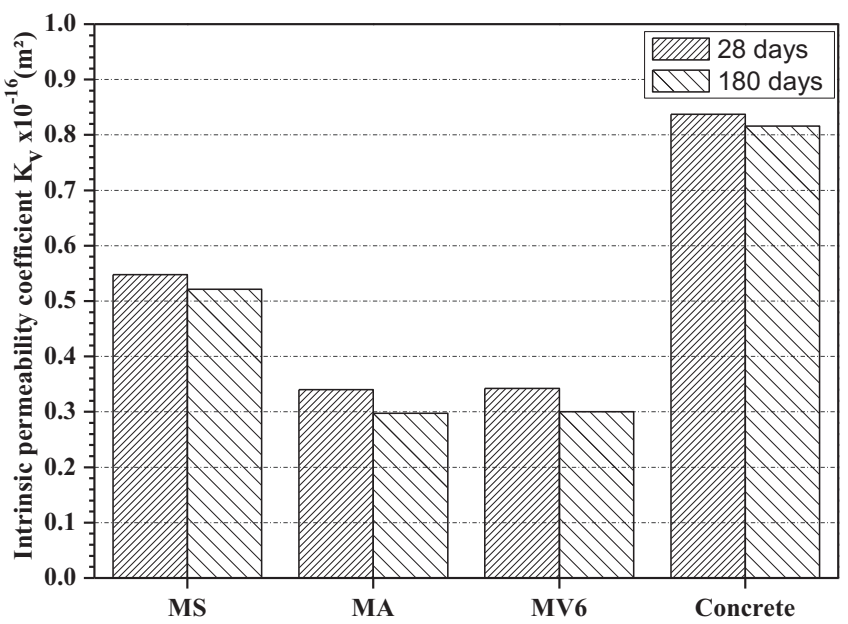

Fig. 19. Intrinsic permeability coefficient.
Table 5

Covercrete classification gas permeability [44].

\begin{tabular}{lll}
\hline Quality grade of concrete & $\mathrm{K}\left[10^{-16} \mathrm{~m}^{2}\right]$ & Quality \\
\hline 1 & $<0.1$ & Excellent \\
2 & $0.1-0.5$ & Very good \\
3 & $0.5-2.5$ & Medium \\
4 & $2.5-12.5$ & Poor \\
5 & $>12.5$ & Very poor \\
\hline
\end{tabular}

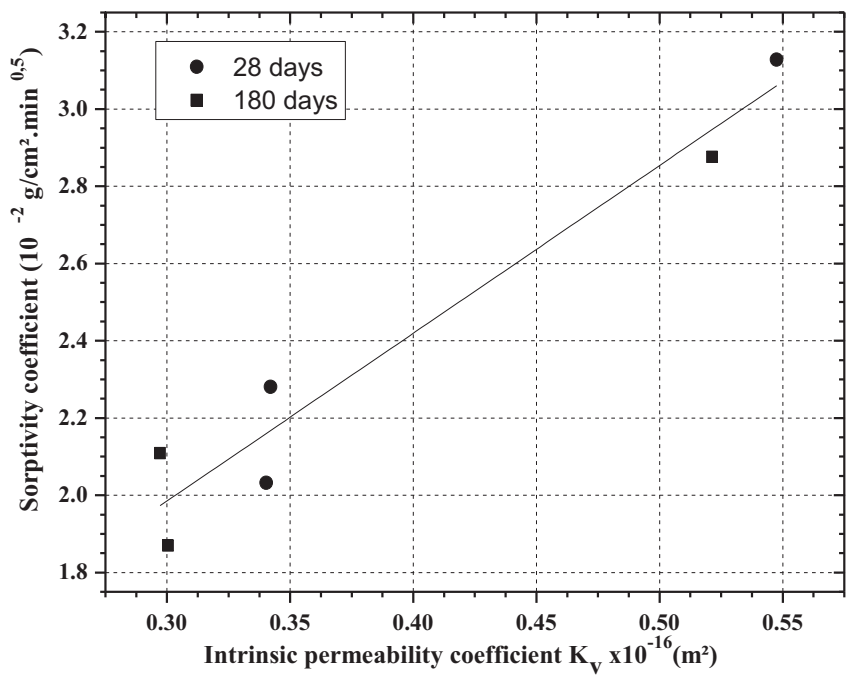

Fig. 20. Relationship between Sorptivity coefficient and intrinsic permeability coefficient.

coefficient with a correlation coefficient of 0.96 . It may be noted that it would be possible to predict the gas permeability from the sorptivity measurements or vice versa. These results confirm the findings of other researchers $[47,48]$.

\subsection{Adhesion}

The adhesion strength of repair mortar and concrete is one (if not the first) of the most important technical characteristics of repair materials. The durability of repair mortar is strongly affected by cracking due to drying shrinkage and the quality of the adhesion with the substrate. A good quality bond between a repair mortar and concrete substrate is an important requirement for assessing efficiency of repair $[49,50]$.

The bond stresses and the failure modes obtained for the different mortars tested are presented in Table 6 . The results show that the adhesion of the simple mortar (MS) with concrete slab is characterized by lower bond strength compared to the fiber mortar (MV6) and admixture mortar (MA). These two last mortars have a bond strength of $15 \%$ and $13 \%$ respectively higher than that of MS mortar. This gain in bond strength seems to be directly related to the rate of cracking caused by the shrinkage which is one of the factors affecting the adhesion between mortar and concrete. Moreover, it can be observed that $80 \%$ of failure occurred in the substrate (cohesive failure) for mortar (MV6), 60\% for mortar MA and only $40 \%$ for mortar MS. These results proved that mortar MV6 is very well bonded to the old concrete.

Furthermore, whatever the type of mortar, the bond strength is greater than the minimum value $(1.5 \mathrm{MPa})$ for structural repair required by the standard EN1504-3 and excellent according to ACI Concrete Repair Guide and others [51,52]. 
Table 6

Bond strengths and failure modes of mortars tested.

\begin{tabular}{|c|c|c|c|c|c|c|}
\hline \multirow[t]{3}{*}{ Simple } & \multicolumn{3}{|c|}{ Bond strength (MPa) } & \multicolumn{3}{|c|}{ Failure mode } \\
\hline & \multicolumn{6}{|c|}{ Mortar } \\
\hline & MS & MA & MV6 & MS & MA & MV6 \\
\hline 1 & 2.18 & 2.52 & 2.57 & Interface & Substrate & Substrate \\
\hline 2 & 2.22 & 2.50 & 2.52 & Substrate & Substrate & Substrate \\
\hline 3 & 2.15 & 2.39 & 2.49 & Interface & Interface & Interface \\
\hline 4 & 2.13 & 2.41 & 2.50 & Mortar & Interface & Substrate \\
\hline 5 & 2.23 & 2.47 & 2.49 & Substrate & Substrate & Substrate \\
\hline Average value & 2.18 & 2.46 & 2.52 & & & \\
\hline
\end{tabular}

\section{Conclusion}

This study investigated the effect of Alfa natural microfiber on compressive strength, flexural strength, shrinkage, sorptivity, gas permeability and bond strength of repair mortar and the following conclusions can be drawn:

- The use of $0.75 \%$ Alfa micro-fiber increases the compressive and flexural strengths by about $15 \%$, and $30 \%$, respectively, because of the mechanical bond between the cement paste and the Alfa micro-fibers.

- Total shrinkage decreases of about $12 \%$. when $0.75 \%$ Alfa microfiber are used

- Fiber mortar MV6 and admixtured mortar MA has a bond strength of respectively $15 \%$ and $13 \%$ higher than that of the control mortar MS. This gain in bond strength seems to be directly related to the low rate of cracking caused by shrinkage which is one of the factors affecting the adhesion between mortar and concrete.

- Gas permeability of different repair mortars mixes remains below that of concrete and hence could provide a good protection of concrete. Mortar MA and MV6 are qualified as offering a very good resistance to gas permeability.

- Sorptivity of mortar MV6 is around 0.023 and 0.021 at 28 and 180 days, respectively, which is approximately $27 \%$ lower than that of MS mortar. This can be a good indicator of the durability of this mortar.

- A good linear correlation exists between sorptivity and intrinsic permeability coefficient and hence it is possible to predict gas permeability from sorptivity measurements and vice versa.

- Adhesion strength of different mortars used is greater than the minimum value (1.50 $\mathrm{MPa}$ ) required by different standards for repair materials.

- From the pull-off test results, mortar MV6 exhibited $80 \%$ of failure in the substrate (cohesive failure) and an increase of $15 \%$ in bond strength compared to MS mortar. These results proved that mortar MV6 is very well bonded to the old concrete.

\section{Conflict of interest}

There is no conflict of interest.

\section{References}

[1] A.S. Al-harthy, M.A. Halim, R. Taha, et al., The properties of concrete made with fine dune sand, Constr. Build. Mater. 21 (2007) 1803-1808.

[2] B. Benchaa, L. Azzouz, E.H. Kadri, S. Kenai, A.S.E. Belaidi, Effect of fine aggregates replacement with desert dune sand on fresh properties and strength of self-compacting mortar, J. Adhes. Sci. Technol. 28 (21) (2014) $2182-2195$.

[3] Saloua El Euch Khay, Jamel Neji, Amara Loulizi, Shrinkage properties of compacted sand concrete used in pavements, Constr. Build. Mater. 24 (2010) 1790-1795.
[4] A. Belferrag, A. Kriker, S. Abboudi, et al., Effect of granulometric correction of dune sand and pneumatic waste metal fibers on shrinkage of concrete in arid climates, J. Cleaner Prod. 112 (2016) 3048-3056.

[5] K.L. Pickering, M.A. Efendy, T.M. Le, et al., A review of recent developments in natural fibre composites and their mechanical performance, Composites Part A 83 (2016) 98-112.

[6] A. Mallat, A. Alliche, Mechanical investigation of two fiber-reinforced repair mortars and the repaired system, Constr. Build. Mater. 25 (2011) 1587-1595.

[7] A.L. Ardeshana, A.K. Desai, Durability of fibre reinforced concrete of marine structures, Int. J. Eng. Res. Appl. 2 (2012) 215-219.

[8] S. Kawashima, S.P. Shah, Early-age autogenous and drying shrinkage behavior of cellulose fiber-reinforced cementitious materials, Cem. Concr. Compos. 33 (2011) 201-208.

[9] J.R. Rapoport, S.P. Shah, Cast-in-place cellulose fiber-reinforced cement paste mortar, and concrete, ACI Mater. J. 102 (2005) 299-306.

10] Coppola, B., Di Maio, L., Courard, L., Scarfato, P. Incarnato, L. Development and use of foamed recycled fibers to control shrinkage cracking of cementitious mortars. 4th WS on New Boundaries of Structural Concrete. ACI Italian Chapter, (Capri, Sept. 29th - Oct, 1st, 2016)

[11] M. Ahmadi, S. Farzin, A. Hassani, M. Motamedi, Mechanical properties of the concrete containing recycled fibers and aggregates, Constr. Build. Mater. 144 (2017) 392-398.

[12] M.S. Meddah, M. Bencheikh, Properties of concrete reinforced with different kinds of industrial waste fibre materials, Constr. Build. Mater. 23 (2009) 31963205.

[13] S. Spadea, I. Farina, A. Carrafiello, F. Fraternali, Recycled nylon fibers as cement mortar reinforcement, Constr. Build. Mater. 80 (2015) 200-209.

[14] S.B. Park, B.C. Lee, "Studies on expansion properties in mortar containing waste glass and fibers, Cem. Concr. Res. 34 (7) (2004) 1145-1152.

[15] G. Ramakrishna, T. Sundararajan, Impact strength of a few natural fibre reinforced cement mortar slabs: a comparative study, Cem. Concr. Compos. 27 (2005) 547-553.

[16] F. Pacheco-Torgal, S. Jalali, Cementitious building materials reinforced with vegetable fibres: A review, Constr. Build. Mater. 25 (2011) 575-581.

[17] M. Ali, A. Liu, H. Sou, et al., Mechanical and dynamic properties of coconut fibre reinforced concrete, Constr. Build. Mater. 30 (2012) 814-825.

[18] M. Sargaphuti, S.P. Shah, K.D. Vinson, Shrinkage cracking and durability characteristics of cellulose fiber reinforced concrete, Mater. J. 90 (1993) 309318 .

[19] P. Soroushian, S. Ravanbakhsh, Control of plastic shrinkage cracking with specialty cellulose fibers, Mater J. 95 (1998) 429-435.

[20] S.K. Sharma, A.A. Kumar, P. Kumar, Micro fiber reinforced cement paste and mortar overlays-a review, Int. J. Pavement Res. Technol. 6 (6) (2013) 765-772.

21] R.D. Toledo Filho, K. Ghavami, M.A. Sanjuán, et al., Free, restrained and drying shrinkage of cement mortar composites reinforced with vegetable fibres, Cem. Concr. Compos. 27 (2005) 537-546.

[22] V. Agopyan, H. Savastano, V.M. John, et al., Developments on vegetable fibrecement based materials in São Paulo, Brazil: an overview, Cem. Concr. Compos. 27 (2005) 527-536.

[23] Banthia N. Report on the physical properties and durability of fiber-reinforced concrete. ACI 544.5 R-10, Reported by ACI Committee. 2010;544:1-3.

[24] A. Kriker, G. Debicki, A. Bali, et al., Mechanical properties of date palm fibres and concrete reinforced with date palm fibres in hot-dry climate, Cem. Concr. Compos. 27 (2005) 554-564.

[25] E.T. Dawood, M. Ramli, Properties of high-strength flowable mortar reinforced with palm fibers, ISRN Civil Eng. (2012) 1-6.

[26] C. Asasutjarit, J. Hirunlabh, J. Khedari, et al., Development of coconut coirbased lightweight cement board, Constr. Build. Mater. 21 (2007) 277-288.

[27] J. Claramunt, M. Ardanuy, J.A. García-Hortal, et al., The hornification of vegetable fibers to improve the durability of cement mortar composites, Cem. Concr. Compos. 33 (2011) 586-595.

[28] D.A. Silva, A.M. Betioli, P.J.P. Gleize, H.R. Roman, J.L.D. Ribeiro, Degradation of recycled PET fibers in Portland cement-based materials, Cem. Concr. Res. 35 (2005) 1741-1746.

[29] P.R. Blankenhorn, M.R. Silsbee, Brad D. Blankenhorn, M. DiCola, K. Kessler, Temperature and moisture effects on selected properties of wood fiber-cement composites, Cem. Concr. Res. 29 (1999) 737-741.

[30] ASTM C 1437, Standard Test Method for Flow of Hydraulic Cement Mortar American Society for Testing and Materials, 2008. 
[31] ASTM C 305, Standard Practice for Mechanical Mixing of Hydraulic Cement pasTes and Mortars of Plastic Consistency, American Society for Testing and Materials, 2006.

[32] ASTM C 348, Standard Test Method for Flexural Strength of Hydraulic-cement Mortars, American Society for Testing and Materials, 2008.

[33] ASTM C 349, Standard Test Method for Compressive Strength of Hydrauliccement Mortars (Using Portions of Prisms Broken in Flexure), American Society for Testing and Materials, 2008.

[34] NF P15-433. Methods of cement testing. Determination of shrinkage and swelling. 1994

[35] F.U.A. Shaikh, Mechanical and durability properties of fly ash geopolymer concrete containing recycled coarse aggregates, Int. J. Sustainable Built Environ. 5 (2016) 277-287.

[36] R. Chaïd, S. Kenaï, H. Zeroub, et al., Microstructure and permeability of concrete with glass powder addition conserved in the sulphatic environment, Eur. J. Environ. Civil Eng. 19 (2015) 219-237.

[37] XP P18-463. Testing gas permeability on hardened concrete. 2011

[38] EN 1542. Products and systems for the protection and repair of concrete structures-Test methods-Measurement of bond strength by pull-off. European Standard; 1999

[39] EN 1766. Products and Systems for the Protection and Repair of Concrete Structures. Test Methods. Reference Concretes for Testing. European Standard; 2000.

[40] Development of Specifications and Performance Criteria for Surface Preparation Based on Issues Related to Bond Strength. B. Bissonnette, L. Courard, A. Garbacz, A. Vaysburd, K. von Fay, B. Robertson. Report ST-2072886-1, Bureau of Reclamation, U.S. Department of Interior, (2017) 198 p.

[41] A.M. Soliman, M.L. Nehdi, Effect of natural wollastonite microfibers on earlyage behavior of UHPC, J. Mater. Civ. Eng. 24 (7) (2012) 816-824.
[42] E. Campello, M.V. Pereira, F. Darwish, The effect of short metallic and polymeric fiber on the fracture behavior of cement mortar, Procedia Mater. Sci. 3 (2014) 1914-1921.

[43] M. Ramli. Behavior of flowable high strength concrete repair material for sustainable engineering construction. I.C.B.E.D.C. 2008:444-460.

[44] E.T. Dawood, M. Ramli, High strength characteristics of cement mortar reinforced with hybrid fibres, Constr. Build. Mater. 25 (2011) 2240-2247.

[45] M. Ramli, W.H. Kwan, N.F. Abas, Strength and durability of coconut-fiberreinforced concrete in aggressive environments, Constr. Build. Mater. 38 (2013) 554-566.

[46] H.S. Ramaswamy, B.M. Ahuja, S. Krishnamoorthy, Behaviour of concrete reinforced with jute, coir and bamboo fibres, Int. J. Cem. Compos. Lightweight Concret. 5 (1983) 3-13.

[47] A. Dinku, H.W. Reinhardt, Gas permeability coefficient of cover concrete as a performance control, Mater. Struct. 30 (1977) 387-393.

[48] R. Torrent, G. Frenzer. A method for the rapid determination of the coefficient of permeability of the "covercrete". International Symposium Non-Destructive Testing in Civil Engineering, 1995:985-992.

[49] L. Czarnecki. Adhesion-A challenge for concrete repair. 2nd International Conference on Concrete Repair, Rehabilitation and Retrofitting ICCRRR-2; Cape Town, South Africa, 24-26 November, 2008; p. 343.

[50] M. Mohammadi, R.M. Moghtadaei, N.A. Samani, Influence of silica fume and metakaolin with two different types of interfacial adhesives on the bond strength of repaired concrete, Constr. Build. Mater. 51 (2014) 141-150.

[51] G. Xiong, J. Liu, G. Li, A way for improving interfacial transition zone between concrete substrate and repair materials, Cem. Concr. Res. 32 (2002) 1877-1881.

[52] B.A. Tayeh, B.H.A. Bakar, M.A.M. Johari, The relationship between substrate roughness parameters and bond strength of ultra-high-performance fiber concrete, J. Adhes. Sci. Technol. 27 (2013) 1790-1810. 